OPEN ACCESS

Edited by:

Ana Filipa Silva,

Polytechnic Institute of Maia, Portugal

Reviewed by:

Ana Ruivo Alves,

University of Beira Interior, Portugal

Bing Zheng,

Tangshan Normal University, China

*Correspondence:

Luo Jiong

784682301@qq.com

Specialty section:

This article was submitted to Movement Science and Sport

Psychology,

a section of the journal

Frontiers in Psychology

Received: 19 April 2021 Accepted: 04 November 2021 Published: 20 December 2021

Citation:

Lian Y, Peijie C, Kun W, Tingran Z, Hengxu $L$, Jinxin $Y$, Wenyun $L$ and Jiong $L$ (2021) The Influence of Family Sports Attitude on Children's Sports Participation, Screen Time, and Body

Mass Index.

Front. Psychol. 12:697358. doi: 10.3389/fpsyg.2021.697358

\section{The Influence of Family Sports Attitude on Children's Sports Participation, Screen Time, and Body Mass Index}

\author{
Yin Lian',2, Chen Peijie ${ }^{3}$, Wang Kun1, Zhang Tingran 1,4, Liu Hengxu1, Yang Jinxin', \\ Lu Wenyun ${ }^{3}$ and Luo Jiong ${ }^{1 *}$
}

\begin{abstract}
'Research Center for Exercise Detoxification, College of Physical Education, Southwest University, Chongqing, China, ${ }^{2}$ Chongqing Medical and Health School, Chongqing, China, ${ }^{3}$ Leisure College, Shanghai University of Sport, Shanghai, China, ${ }^{4}$ Integrative Exercise Physiology Laboratory, Department of Physical Education, Jeonbuk National University, Jeonju, South Korea
\end{abstract}

Background: Children's physical health is an important resource for a country's future construction. However, researchers found that the physical fitness of young children around the world has declined during the two decades, from 1992 to 2012 . The decline in the physique of young children has caused widespread concern around the world. Children's main living places are families and kindergartens, so this research explores the impact of family factors on children's body mass index (BMI) from the perspective of family attitudes, children's sports participation, and screen time.

Methods: A cross-sectional study was used to conduct a questionnaire survey of children in China. A total of 600 children were investigated, and 589 valid questionnaires were obtained. SPSS21.0 statistical analysis software was used for descriptive analysis, mean comparison, and correlation analysis of the data. AMOS 21.0 was used to construct a structural equation model and carry out path analysis.

Results: (1) There are significant differences in children's family sports attitude, sports participation, screen time, and BMl with different family structures, and parents' education levels. (2) Family sports attitude is significantly positively correlated with parents' education levels and children's sports participation, and negatively correlated with children's screen time and BMI. (3) Children's sports participation and screen time play a chain-mediating role between family sports attitude and children's BMI, and the role is a complete mediating role. Therefore, family sports attitudes can affect children's physical health by affecting children's sports participation and screen time. To promote children's physical health, we should pay attention to the intervention of family sports attitude. (4) The mediating effects of exercise participation and screen time are similar in different family structures, so the structure of this study can be applied to different family structures. 
Conclusions: Children's family sports attitude, sports participation, and screen time can affect children's BMI. Children's screen time and sports participation play a chainmediating role in the influence of family sports attitudes on the path of children's BMI. The results of this study will provide a useful reference for teachers and parents to control children's physical health.

Keywords: children, family sports attitude, parents' education level, body mass index, screen time

\section{INTRODUCTION}

Children are the fundamental guarantee of human sustainable development ${ }^{1}$. As an important resource for the future construction of a country, their physical health is a strategic issue directly related to the future and destiny of the country (Liu et al., 2021). Children's physical fitness has always been a health issue of global concern. A survey of children and adolescents aged $2-19$, including toddlers, showed that obesity rates rose by $6.9 \%$ for males and $6.4 \%$ for females in developed countries; obesity rates in developing countries rose by $4.8 \%$ for males and 5.0\% for a female between 1980 and 2013 (Ng et al., 2014). According to the 2014 National Physical Fitness Monitoring Survey, the level of morphological indicators such as height has improved in China, while the level of physical fitness has decreased, ranging from 0.1 to $2.3 \%$. The Report on Childhood Obesity in China points out that the obesity rate of children in large- and medium-sized cities alone is $4.3 \%$. Without effective intervention measures, the obesity rate of children will rise to $6 \%$ by 2030 , which seriously threatens children's physical health. Therefore, it is of great significance to pay attention to children's physical quality for the sustainable development of children's physical health (Pooja et al., 2016; Zhang et al., 2017). Since 2000, by the national physical fitness monitoring indicators issued by the state, China has conducted regular and unified tests on the monitored objects nationwide in the form of sampling surveys; children aged 3-6 are the important monitoring objects. The age of 3-6 is a critical period for children's growth and development. A follow-up investigation found that obesity in early childhood can increase the probability of obesity in adulthood (Freedman et al., 2005; Singh et al., 2008). And obesity can cause chronic diseases, such as hypertension, diabetes, and cardiovascular disease (Hu et al., 2004; Reaven, 2011). Therefore, it is of great significance to investigate and monitor children's family environment, sports behavior and shape, quality, function, and other content indicators at this stage (Zhang et al., 2019).

Among physical measurement indexes, Body Mass Index (BMI), which is calculated as BMI $=$ weight $(\mathrm{kg}) /$ height $(\mathrm{m})^{2}$, is an objective index commonly used in the world to measure the degree of body fat and thinness (Dietz and Robinson, 1998). BMI, as one of the important indicators for child nutrition monitoring and obesity screening, has reached broad consensus on theory and practice. Many organizations and

\footnotetext{
${ }^{1}$ Research Group of Chinese National Physical Fitness Monitoring System, Department of Science and Education, General Administration of Sport of China Study on Chinese National Physical Fitness Monitoring System [M]. Beijing: Beijing Sport.
}

countries around the world have established the standard curve of BMI percentile and the threshold of overweight and obesity screening for preschool children, such as the International Obesity Organization (IOTF) (Cole and Lobstein, 2012), WHO (de Onis et al., 2007). Relevant research found that BMI was not only significantly correlated with the occurrence of hyperglycemia, hypertension, hyperlipidemia, and other diseases but also can directly reflect the body fat level of the human body. This index was also significantly correlated with the health of children and adolescents after adulthood (Carson et al., 2016, 2017). Due to their cognitive characteristics, children's cognitive ability is lower than that of adults. Generally, children cannot rely on direct experience when acquiring information, and they need to rely more on people around them to provide information. Studies have found that parents' upbringing, static screen time was too long, and inadequate activity would lead to children's physical deterioration, and parents' upbringing was the integrated embodiment of its education behavior and idea, which also was a kind of performance in the process of child-rearing behaviors and tendency; beyond that, family structure and the cultural level can significantly affect their parents' upbringing (Zhou et al., 2014; Lu et al., 2015; Chen et al., 2020). Although there are many studies on the influence of the family environment on the next generation's sports healthy behavior, previous studies mainly focused on the influence of the family capital on its healthy behavior. Moreover, very few studies focused on the influence of family sports attitude on their sports behavior, screen time, and BMI. In addition, previous studies on children's BMI mainly focused on descriptive analysis without effectively exploring its path relationship. Therefore, the path relationship between the influence of family sports attitude on children's BMI, especially in different family structures, remains to be further studied. Therefore, based on the analysis of previous studies and by the characteristics of children's growth and development, this study constructed a theoretical framework model of family sports attitude, affecting children's BMI. This study explored the influence mechanism of family sports attitude on children's BMI.It is found that family sports attitudes can affect children's physical health by influencing children's screen time and sports participation. The results of this study will provide a useful reference for the rational design and planning of children's physical and mental health courses, and it will provide a useful reference for improving children's physical activity level and preventing children's obesity. Therefore, based on the analysis of previous studies and by the characteristics of children's growth and development, 
this study constructed a theoretical framework model of family sports attitude affecting children's BMI, thus providing a useful reference for the future design and planning of children's physical and mental health courses, promoting their physical activity levels and the prevention of children's obesity in the future.

\section{LITERATURE REVIEW}

\section{Family Sports Attitudes With Children's Physical Activity and Screen Time}

Social psychological studies have proved that values affect attitudes and attitudes affect behaviors. Sports attitude is an outer variable, which can only affect children through sports behavior. The characteristics of children's physiological cognition lead to the need for nurturing children to provide them with sports experience and information, and sports are highly infectious. Researchers have found that children from families with supportive attitudes toward physical activities were significantly better than those who did not (Dong et al., 2018). Therefrom, family sports attitude would have a certain influence on children's physical activity participation behavior and psychology (Timperio et al., 2013). It was found that children were more affected by the feedback of parents' sports evaluation, and they were more susceptible to the influence of peers in adolescence. From that, parents play a key role in the influence of children's physical activity behavior in early childhood (Fu and Li, 2004; Brown and Larson, 2009). Compared with children without parental support, children with parental support were more likely to participate in sports activities and believed that they have the better athletic ability (Budde et al., 2008; Best, 2012). A study that followed daily activities of 155 children aged 4-7 for 3 years found a high correlation between low levels of gaming activity and high BMI, while the high level of physical activity was positively correlated with the BMI-Z score in preschoolers (Foster et al., 2018; Hoare et al., 2019). The BMI of children with moderate to highintensity physical activity was significantly lower than that of children with low-intensity physical activity (Thivel et al., 2013; Beaulieu et al., 2016). However, there are also inconsistent results with the above studies. Researchers conducted a randomized controlled intervention experiment on children in 36 nurseries in Douglas, Scotland, three times a week, and found that the BMI of the children in the low-intensity physical activity experimental group was not lower than that of the control group. However, there was a significant difference in BMI between the moderate-to-high-intensity group and the control group, so the amount of moderate-to-high-intensity physical activity would significantly affect the BMI of children (Reilly et al., 2006). Fitzgibbon et al. (2004) found that moderate to high-intensity hip-hop was effective in reducing subsequent increases in BMI in preschoolers in Chicago, Illinois, but had no significant effect in Latin America. In addition, sedentary behavior has also attracted a lot of attention from researchers, especially since the screen time of sedentary behavior has almost become the focus (Thivel et al., 2013). The survey found that the average screen time of primary school students in Hong Kong was $4 \mathrm{~h}$ per day on weekdays and $6 \mathrm{~h}$ on weekends there was a positive correlation between screen time and BMI among children (Shi et al., 2020). Three-year-old children with more than $8 \mathrm{~h}$ of screen time per week had an increased risk of obesity at the age of 7 , a finding found in another study, which also reduced BMI, triceps sebum thickness, and abdominal circumference when screen time was reduced (Van Ekris et al., 2016).

\section{Parents' Education Level and Children's BMI}

As the core of the family and the first teacher of children, the influence of parents on their children's behavior and attitude is the focus of scholars' research. Parents' education levels are an important background characteristic that affects children's development. A large number of studies have reported that parents' socioeconomic status is closely related to their children's cognitive ability, social emotion, and physical health. The indicators of social and economic status include parents' education levels, income, occupation, etc., among which parents' education levels are a stable and important indicator (Bradley and Corwyn, 2002; Matthews and Gallo, 2011). Cheng et al. (2020) found that a mother's occupation and length of education had a significant impact on the BMI of her children. The higher her occupational class and status, the longer her education, the lower the BMI of her children. The more time children spent in physical activity with their parents, the lower their BMI was (Cheng et al., 2020). In the study of family social economy and BMI of children and adolescents, Shi et al. (2021) found that the education level of parents can significantly affect the BMI of children and adolescents, and the higher the education level of parents, the lower the probability of the children's BMI being obese. In consequence, the mechanism of the parental educational level in the influence of family sports attitude on children's BMI needs to be further studied.

\section{Family Structure and Children's BMI}

Early childhood is a critical period for the development of physical health. When children choose physical activities at a young age, they can only complete them under the guidance of caregivers, so caregivers play a pivotal role in this process, and the family environment in which children grow up and its composition are of great importance. The researchers found that the physical activity style of the caregivers, the degree of support and supervision for their children's physical activity, and the parenting methods would all affect children's sports participation (Zhang et al., 2017). Therefore, the composition of family members and the time and the way of accompanying children in their growth process have a significant impact on children's sports participation and eating habits, and these factors are related to children's BMI. There are mainly nuclear families living with their parents and non-nuclear families, such as singleparent families, intergenerational families, and three-generation families. Children with different family structures have different primary caregivers, and children's sports participation and other 
factors are different due to different parenting styles and health concepts. In recent years, the influence of family structure on children's health behaviors has gradually attracted the attention of scholars. However, the focus is mainly on the mental health problems caused by intergenerational rearing and single-parent families, while the influence of family structure on children's physical health and sports behaviors is rarely studied (Basterfield et al., 2011). Then, the specific mechanism of children's health differences caused by family sports attitude is still unclear, and the influence of different family structures on children's physical fitness needs to be further studied.

In conclusion, first, previous studies have confirmed that family sports attitude has a certain influence on children's physical activity and screen time. Second, exercise participation and screen time were important factors affecting children's BMI. However, whether exercise participation and screen time have a mediating effect on the influence of sports attitude on children's BMI has not been verified. Third, since the family structure can influence children's sports behavior, it has not been confirmed whether the influence path of sports attitude on children's BMI will change in different family structures, that is, nuclear family and non-nuclear family. Because of this, this study hypothesized that $\mathrm{H} 1$ : family sports attitude was negatively correlated with infant BMI; Hypothesis H2: children's activity participation and screen time played a mediating role in the relationship between family sports attitude and children's BMI.

\section{MATERIALS AND METHODS}

\section{Participants}

The sample was 589 children aged 3-6 years (mean $=4.55$, $\mathrm{SD}=1.16), 49.9 \%$ of girls, participated in this study with the permission of their guardians. Table 1 summarizes the demographic characteristics of the participants.

\section{Instrument}

The instrument of this research was a questionnaire, which was designed and based on a large number of research literature; the following three parts were sorted out and formed:

\section{Personal Background}

The content includes children's gender, age, height, weight, and other actual basic information, and the corresponding BMI is calculated according to their height and weight.

\section{Children's Sports Participation}

In this part, the exercise participation calculation formula used by Fox (1999) was adopted: exercise participation = exercise frequency $\times$ (average exercise intensity + exercise duration). The higher the value, the higher the exercise participation degree. This part includes the number of days for children to have screen activities in a week, the number of times of exercise in a week, activity intensity, and activity time, etc. Specifically, the classification of exercise time is as follows: 1 means $30 \mathrm{~min}$ or less, 2 means 31-60 min, and 3 means $61-90 \mathrm{~min}, 4$ means $91-$ $120 \mathrm{~min}$ of exercise, 5 means $121 \mathrm{~min}$ or more. Exercise intensity

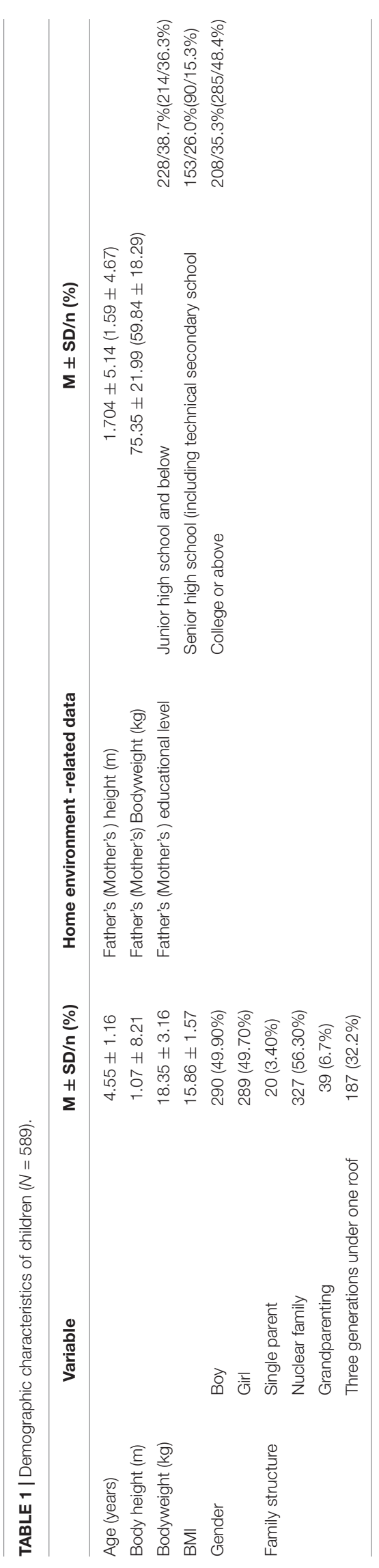


is also divided into five levels: 1 means not tired at all, 2 means not tired, 3 means a little tired, 4 means very tired, 5 means very tired. The frequency of exercise is the number of exercises per week: 1 means less than one time per week, 2 means one to two times per week, 3 means three to four times per week, 4 means five to six times per week, and 5 means more than six times per week.

\section{Home Environment}

This part includes the basic information of children's main caregivers, occupation, education level, physical exercise frequency, and attitude toward sports. The physical exercise attitude scale contains nine items, such as Do you think your child's physical fitness is enhanced by playing sports games. The scale was quantified by a Likert five-point scale, according to the options "disapprove, not very agree, general, somewhat agree, and strongly agree"; the scale was rated as 1-5 points, respectively. The higher the total score, the more support the parents have for children's sports. The pretest of the scale showed that the retest reliability was high, and the overall Cronbach $\alpha$ coefficient was 0.87 . The overall verification results of the measurement model were as follows: $\chi 2 / \mathrm{df}=1.84, \mathrm{RMSEA}=0.03$, AGFI $=0.98$, $\mathrm{CFI}=0.99$, TLI $=0.99$, IFI $=0.99, \mathrm{GFI}=0.99$, which shows that the questionnaire has good measurement validity and reliability.

\section{Statistical Analysis}

SSPS Statistics 21.0 was used for the statistical analysis. After the Shapiro-Wilk normality test, the independent sample $t$-test and one-factor ANOVA were used to analyze the differences in demographic variables. Pearson's cross-production correlation was used in parents' education levels, family sports attitude, sports participation, screen time, and children's BMI. AMOS 21.0 was used to construct the structural equation model and conduct path analysis. The mediation test process proposed by Gerbing and Anderson (1988) was used to explore the mediation effect. First, the independent variable had an impact on the dependent variable, and the regression coefficient was significant. Second, the independent variable affected the intermediary variable, and the regression coefficient was significant. Third, the joint influence of the independent variable and intermediary variable on the dependent variable was significant. The significance level of all indexes was set to $\alpha=0.05$.

\section{RESULTS}

\section{Demographical Variance Analysis of Sports Attitude and Sports Behavior}

The results of the independent sample $t$-test (Table 2) show that, in terms of gender, there was no difference in boys' and girls' family attitudes toward physical activity $(T=0.39, p>0.05)$. There was no difference in the physical activity behavior between boys and girls $(t=0.99, p>0.05)$. There was no gender difference in screen time $(t=1.03, p>0.05)$. There was no gender difference in infant BMI $(T=1.23, p>0.05)$. The results of analysis of variance showed that: (1) In terms of a mother's education level, there were differences in the family sports attitude score, children's sports participation, screen time, and children's BMI among different mothers' education levels. Specifically, the scores of the mother with primary school education were lower than those with high school education, while those with high school education were lower than those with a college education or above $(F=49.74, p<0.01)$. There were also significant differences

TABLE 2 | Demographical variance analysis of sports attitude and sports behavior $(N=589)$.

\begin{tabular}{|c|c|c|c|c|c|c|c|c|}
\hline \multirow[t]{2}{*}{ Variable } & \multicolumn{2}{|c|}{ Family sports attitude } & \multicolumn{2}{|c|}{ Sports participation } & \multicolumn{2}{|c|}{ Screen time } & \multicolumn{2}{|c|}{ Children's BMI } \\
\hline & $\mathbf{M}$ & SD & $\mathbf{M}$ & SD & $\mathbf{M}$ & SD & $\mathbf{M}$ & SD \\
\hline Boy & 31.80 & 7.08 & 23.25 & 15.08 & 5.30 & 1.89 & 15.94 & 1.57 \\
\hline Girls & 31.55 & 8.11 & 22.06 & 13.83 & 5.13 & 1.96 & 15.44 & 1.56 \\
\hline T & 0.39 & & 0.99 & & 1.03 & & 1.23 & \\
\hline Primary school (A) & 28.04 & 6.52 & 18.78 & 12.66 & 5.65 & 1.70 & 16.87 & 1.52 \\
\hline Middle school to high school (B) & 31.68 & 8.67 & 20.14 & 12.46 & 5.26 & 1.91 & 15.74 & 1.69 \\
\hline College or above $(\mathrm{C})$ & 34.43 & 6.88 & 26.19 & 15.38 & 4.85 & 2.03 & 15.14 & 1.11 \\
\hline \multirow[t]{2}{*}{ F (mother) Multiple comparison } & \multicolumn{2}{|c|}{$49.74^{\star \star \star}$} & \multicolumn{2}{|l|}{$18.67^{\star \star \star}$} & \multicolumn{2}{|c|}{$10.98^{\star \star \star}$} & \multicolumn{2}{|c|}{$98.14^{\star \star \star}$} \\
\hline & \multicolumn{2}{|c|}{$\mathrm{C}>\mathrm{B} ; \mathrm{B}>\mathrm{A}$} & \multicolumn{2}{|l|}{$C>A$} & \multicolumn{2}{|c|}{$A>C$} & \multicolumn{2}{|c|}{$A>B ; B>C$} \\
\hline Primary school (a) & 28.83 & 7.87 & 20.68 & 13.52 & 5.42 & 1.88 & 16.29 & 1.82 \\
\hline Middle school to high school (b) & 33.34 & 7.21 & 23.17 & 15.24 & 5.27 & 1.93 & 15.60 & 1.19 \\
\hline College or above (c) & 33.58 & 6.65 & 24.21 & 14.62 & 4.91 & 1.96 & 15.57 & 1.43 \\
\hline \multirow[t]{2}{*}{ F (father) Multiple comparison } & \multicolumn{2}{|c|}{$28.39^{\star \star \star}$} & \multicolumn{2}{|l|}{$3.48^{\star \star \star}$} & \multicolumn{2}{|c|}{$3.95^{\star \star}$} & \multicolumn{2}{|c|}{$24.35^{\star \star \star}$} \\
\hline & \multicolumn{2}{|c|}{$c>a ; b>a$} & \multicolumn{2}{|l|}{$c>a$} & \multicolumn{2}{|l|}{$c>a$} & \multicolumn{2}{|c|}{$c>a ; b>a$} \\
\hline Single parent (I) & 24.45 & 12.70 & 35.90 & 12.84 & 4.25 & 2.17 & 15.23 & 1.07 \\
\hline Nuclear family (II) & 31.94 & 7.26 & 13.59 & 6.93 & 5.20 & 1.96 & 15.92 & 1.63 \\
\hline Grandparenting (III) & 29.56 & 9.21 & 34.26 & 12.77 & 5.10 & 2.05 & 15.47 & 1.86 \\
\hline Three generations under one roof (IV) & 32.44 & 6.85 & 32.00 & 13.38 & 5.33 & 1.81 & 15.88 & 1.44 \\
\hline \multirow[t]{2}{*}{ F (family structure) Multiple comparison } & \multicolumn{2}{|l|}{$6.02^{\star \star \star}$} & \multicolumn{2}{|l|}{$2.29^{\star \star \star}$} & \multicolumn{2}{|c|}{$1.58^{\star \star}$} & \multicolumn{2}{|l|}{1.74} \\
\hline & \multicolumn{2}{|l|}{ III > I; } & \multicolumn{2}{|l|}{$\mathrm{I}>\mathrm{IV}$} & \multicolumn{2}{|c|}{ IV > I; II > I } & & \\
\hline
\end{tabular}

${ }^{*} p<0.05,{ }^{* *} p<0.01$, and ${ }^{* * *} p<0.001$. 
TABLE 3 | Analysis of the correlation among family sports attitude, parents' education levels, sports participation, screen time, and children's BMI ( $N$ = 589).

\begin{tabular}{|c|c|c|c|c|c|c|c|c|}
\hline Variables & $\mathbf{M}$ & SD & 1 & 2 & 3 & 4 & 5 & 6 \\
\hline 1. Children's BMI & 15.86 & 1.58 & - & & & & & \\
\hline 2. Family sports attitude & 32.10 & 8.22 & $-0.23^{\star \star \star}$ & - & & & & \\
\hline 3. Mother's education level & 2.12 & 0.91 & $-0.37^{\star \star \star}$ & $0.19^{\star \star \star}$ & - & & & \\
\hline 4. Father's education level & 1.97 & 0.86 & $-0.18^{\star \star \star}$ & $0.09^{* \star}$ & $0.55^{\star \star \star}$ & - & & \\
\hline 5. Sports participation & 22.57 & 14.43 & $-0.62^{\star \star \star}$ & $0.32^{\star \star \star}$ & $0.24^{\star \star \star}$ & $0.11^{\star \star \star}$ & - & \\
\hline 6. One week of screen time & 5.12 & 1.94 & $0.49^{\star \star \star}$ & $-0.15^{\star \star \star}$ & $-0.17^{\star \star \star}$ & -0.08 & $-0.49^{\star \star \star}$ & - \\
\hline
\end{tabular}

${ }^{*} p<0.05,{ }^{* *} p<0.01$, and ${ }^{* * *} p<0.001$.

in children's sports participation between fathers with different education levels $(F=18.67, p<0.01)$. Children with fathers' education levels had the highest sports participation in college or above, followed by children with fathers' education levels in middle to high school. There was no significant difference in children's sports participation between fathers' education levels in middle and high school and primary school children. The screen time of children was significantly different only between primary school and college or above groups. The screen time of mothers with primary school education was significantly higher than that of college or above groups $(F=10.98, p<0.01)$. In terms of children's BMI, there were differences between mothers with different education levels. The BMI of children whose mothers had primary school education was significantly higher than that of those from middle school to high school, and the BMI of children whose mothers had middle school to high school education was higher than that of children whose mothers had a college education or above. (2) In terms of fathers' education levels, there was a significant difference in sports attitude among families with different fathers' education levels $(F=28.39, p<0.01)$. The score of a father's education from middle school to high school was significantly higher than that of primary school, and there was no significant difference in the score of family sports attitude when a father's education was higher than middle school $(p>0.05)$. There were also differences in children's sports participation among fathers with different education levels. Fathers' education levels in college and above were significantly higher than those in primary school $(F=3.48, p<0.01)$, while there was no difference between fathers' education levels in primary school and middle school to high school $(p>0.05)$. In terms of screen time, there was no difference between fathers with college or above education background and those with middle school to a high school education level $(F=3.95, p<0.01)$, while there was no difference between fathers with middle school to high school and primary school education levels $(p>0.05)$. In terms of BMI of children, the father's education level from middle school to high school was significantly lower than that of primary school, and the father's education level from university or above was also significantly lower than that of primary school $(F=24.35, p<0.01)$. There was no difference in BMI of children between a father's education level from middle school to high and those education levels from a college or above $(p>0.05)$. (3) Family structure: there were differences in family sports attitude, sports participation, and screen time among children with different family structures, but there was no significant difference in BMI. Multiple comparisons showed that the scores of family sports attitude in families with parents living together, intergenerational parenting, and three generations living in the same house were significantly higher than those in single-parent families $(F=6.02, p<0.01)$. The results showed that the children's sports participation of three generations in the same family, intergenerational parenting, and single-parent family was significantly higher than that of a small family $(F=152.69, p<0.05)$. Screen static time per week in families with three generations and parents living together was higher than that in single-parent families $(F=1.58, p<0.05)$.

\section{Correlation Analysis of Family Sports Attitude, Parents' Education Levels, Sports Participation, Screen Time, and Children's BMI}

Correlation analysis showed (Table 3) that there were significant correlations among the variables. There was a significant negative correlation between family sports attitude, sports participation, parents' education levels, and children's BMI, and there was a significant positive correlation between screen time and children's BMI. Hypothesis $\mathrm{H} 1$ of this study was confirmed. There was a significant positive correlation between sports participation and family sports attitude $(r=0.32)$. There was a significant negative correlation between family sports attitude and children's screen time $(r=-0.15)$. There was a significant negative correlation between family sports attitude and children's BMI $(r=-0.23)$.

\section{Linear Regression of Family Sports Attitude, Sports Participation, Screen Static Time, and Children's BMI}

The results of linear regression showed that family sports attitude was negatively correlated with children's BMI. Sports participation was negatively correlated with young children's BMI. One week of static screen time was positively correlated with children's BMI. And they all reached a significant level (Table 4).

\section{Path Relationship Analysis of Family Sports Attitude, Sports Participation, Screen Static Time, and Children's BMI}

The relationship of family sports attitude, sports participation, screen time, and children's BMI, the mediating effect between screen time, and exercise participation were examined by Wen 
TABLE 4 | Linear regression of family sports attitude, sports participation, screen static time, and children's BMI.

\begin{tabular}{|c|c|c|c|c|c|c|c|c|c|}
\hline & \multicolumn{3}{|c|}{ Family sports attitude } & \multicolumn{3}{|c|}{ Sports participation } & \multicolumn{3}{|c|}{ One week of screen time } \\
\hline & $R^{2}$ & $\beta$ & $P$ value & $R^{2}$ & $\beta$ & $P$ value & $R^{2}$ & $\beta$ & $P$ value \\
\hline BMl & 0.02 & -0.14 & 0.001 & 0.38 & -0.62 & $<0.001$ & 0.24 & 0.49 & $<0.001$ \\
\hline
\end{tabular}

and Ye mediating effect test procedures (Zhonglin and Baojuan, 2014). Figure 1 shows a structural equation model testing the mediating effect of exercise participation and screen time. The structural equation model contains four potential variables, and the results show that the fitting indexes of the structural equation model are as follows: $\mathrm{x} 2 / \mathrm{df}=1.84, \mathrm{df}=1, \mathrm{RMSEA}=0.03$, AGFI $=0.98$, CFI $=0.99$, TLI $=0.99$, IFI $=0.99$, which indicated that a model can be established well. Figure 1 shows the standardized coefficient in the mediation model diagram, and Table 5 shows the results of indirect effects. As shown in Table 5, the confidence interval of each mediation path does not contain 0 , so the mediation effect is significant. Hypothesis H2 in this study is valid. As shown in Figure 1, the direct effect of family sports attitude and children's BMI in the model was not significant $(r=-0.04, p>0.05)$, but the negative prediction effect of family sports attitude and screen time was significant $(r=-0.14, p<0.001)$. Family sports attitude and children's sports participation had a significant positive predictive effect $(r=0.25, p<0.001)$. The BMI of children was predicted negatively by sports participation ( $r=0.49, p<0.001)$, while the screen time could predict BMI positively $(r=0.25, p<0.001)$. From the significant levels and the standardized path coefficient $b$ values in the structural model in Figure 1, it is not difficult to find that screen time and sports participation in the model play a mediating role between family sports attitude and children's BMI, and the mediating role includes three paths: The single mediating effect of screen time and sports participation, and the chain mediating effect of screen time $\rightarrow$ exercise participation. To verify the mediating effect of sports participation and screen time between family sports attitude and children's BMI, nonparametric percentile Bootstrap was used to test the significance of mediating effect. The original data were sampled 2,000 times, and a 95\% CI was estimated. If the confidence interval did not include 0 , the mediating effect was significant. The results in Table 5 show that screen time (95\% CI: -0.021 , -0.006) and sports participation (95\% CI: $-0.045,-0.028)$ played a complete mediating role between family sports attitude and children's BMI, while screen time $\rightarrow$ sports participation (95\% CI: $-0.046,-0.026)$ played a chain-mediating role. None of the three intervals contain 0 , indicating a significant mediating effect. Therefore, hypotheses $\mathrm{H} 1$ and $\mathrm{H} 2$ of this study have been confirmed.

\section{Difference Test of a Mediation Model in Different Family Structures}

Relevant studies found that different family structures in children's lives can lead to significant differences in children's sports participation, screen time, and BMI. This study verified

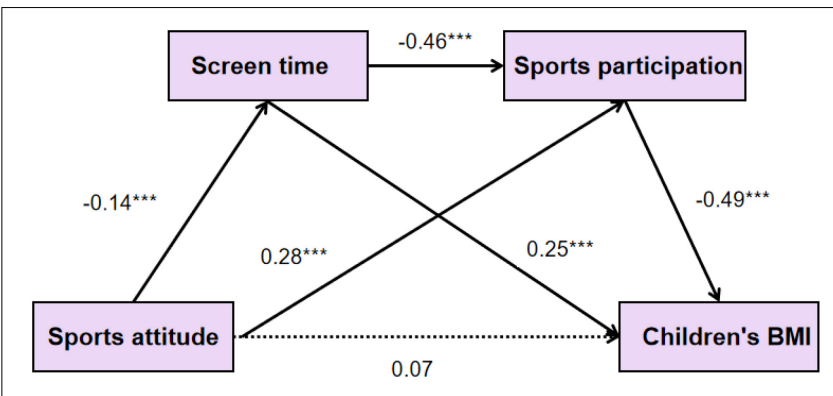

FIGURE 1 | Path relationship between family sports attitude, sports participation, screen static time, and children's BMI.

whether sports participation and screen time have a stable mediating role in different family structures. Firstly, the mediating effects of children's sports participation and screen time in nuclear and non-nuclear families were examined respectively. The results showed that the model fitting indexes of nuclear families were: $\chi 2 / \mathrm{df}=2.51$, AGFI $=0.96$, CFI $=0.99$, TLI $=0.96$, IFI $=0.99$, RMSEA $=0.067$. The model fitting indexes of non-nuclear families were: $\chi 2 / \mathrm{df}=1.67$, AGFI $=0.96$, CFI $=0.99$, TLI $=0.98$, IFI $=0.99$, and RMSEA $=0.052$. The results showed that the fitting indexes of each group were good, which could be compared with different groups of models. Then, the set equivalent model was used to compare the different groups of models, and the results showed that the model had good fitting indexes, and the fitting index difference $\triangle \mathrm{CFI}$ and $\triangle \mathrm{TLI}$ values were less than 0.05 ( $\triangle$ CFI and NTLI were obtained by the difference of TLI and CFI between the nuclear family and the non-nuclear family) (Zhao, 2007). The results show that the mediation model is stable in different family structures.

\section{DISCUSSION}

\section{Analysis of Influencing Factors of Infant BMI, Family Sports Attitude, Sports Participation, and Screen Time}

This study found no gender differences in children's BMI, family sports attitude, weekly sports participation, and static screen time, which is consistent with the results of the Xinran Shi's study (Shi et al., 2021). At the same time, this study found that children with different family structures have significant differences in sports attitudes, screen time, and sports participation (Figure 2). Further analysis found that children with single-parent family structure scored the lowest in family sports attitude, and there were significant differences in living with their parents, grandparenting, and three generations in the same family. 
TABLE 5 | A statistical table of path weight coefficient $(N=589)$.

\begin{tabular}{|c|c|c|c|}
\hline No. & Pathway Boot & Standardized mediating effect value (SE) & Bootstrap $95 \%(\mathrm{Cl})$ \\
\hline 1 & Sports attitude $\rightarrow$ Screen time $\rightarrow$ Children's BMl & $0.01(0.01)$ & $(-0.021,-0.006)$ \\
\hline 2 & Sports attitude $\rightarrow$ Sports participation $\rightarrow$ Children's BMl & $-0.04(0.01)$ & $(-0.045,-0.028)$ \\
\hline 3 & Sports attitude $\rightarrow$ Screen time $\rightarrow$ Sports participation $\rightarrow$ Children's BMI & $-0.04(0.01)$ & $(-0.046,-0.026)$ \\
\hline
\end{tabular}

Previous studies showed that children living in the single-parent family structure were more likely to have physical and mental health problems than those who live in a two-parent family structure (Ledoux et al., 2002; Wang et al., 2012). Quarmby et al. (2011) confirmed that the lower socioeconomic status of single-parent families compared with two-parent families partly explains the poorer physical health of their children. Compared with European and American countries, the major feature of Chinese family structure is grandparenting. There are different conclusions about the advantages and disadvantages of grandparenting. Opponents believe that grandparents are prone to develop bad health habits due to poor health habits and lack of nutrition knowledge. Supporters believe that grandparents' love for their grandchildren, abundant time and energy investment in a company, education, and nurturing experience are all beneficial to the healthy development of grandchildren (Lu et al., 2020). In this study, we found that the sports participation of three-generation families was higher than that of families living with parents only, which may be related to the time advantage of grandparents to pay attention to and accompany their children's activities. Other researchers have suggested that the three-generation family structure is more conducive to the formation of healthy concepts in young children, as the role of family bonding is played by grandparents living in the same family.

In addition, this study found that the higher the mother's education level, the lower the children's BMI. Qian et al. conducted a study on Chinese students aged 8-10 and found that the group whose parents have a low educational level has a low score in dietary habits and nutritional knowledge, while dietary habits are significantly correlated with BMI (Han et al., 2016). Han Hui et al. found a significant correlation between children's food preference risk and their mothers' education levels, and the higher the mother's education level, the lower the risk of children's food preference risk (Qian et al., 2018). The study also found that parents' education levels were negatively correlated with children's screen static time. Researchers also found that the daily screen time of children whose parents have a college education level or above was significantly lower than that of children whose parents have a primary school education level or below. The study also found that children whose parents had college education levels spend more time on moderateintensity activity than children whose parents had middle school education levels or below (Wärnberg et al., 2021). The results of this study are also consistent with those of other studies (Pons et al., 2020). So, the results of this study are not only limited to Chinese children but also consistent with those of Spanish and Caucasian children; the results showed that the educational level of the parents was related to the health habits of children

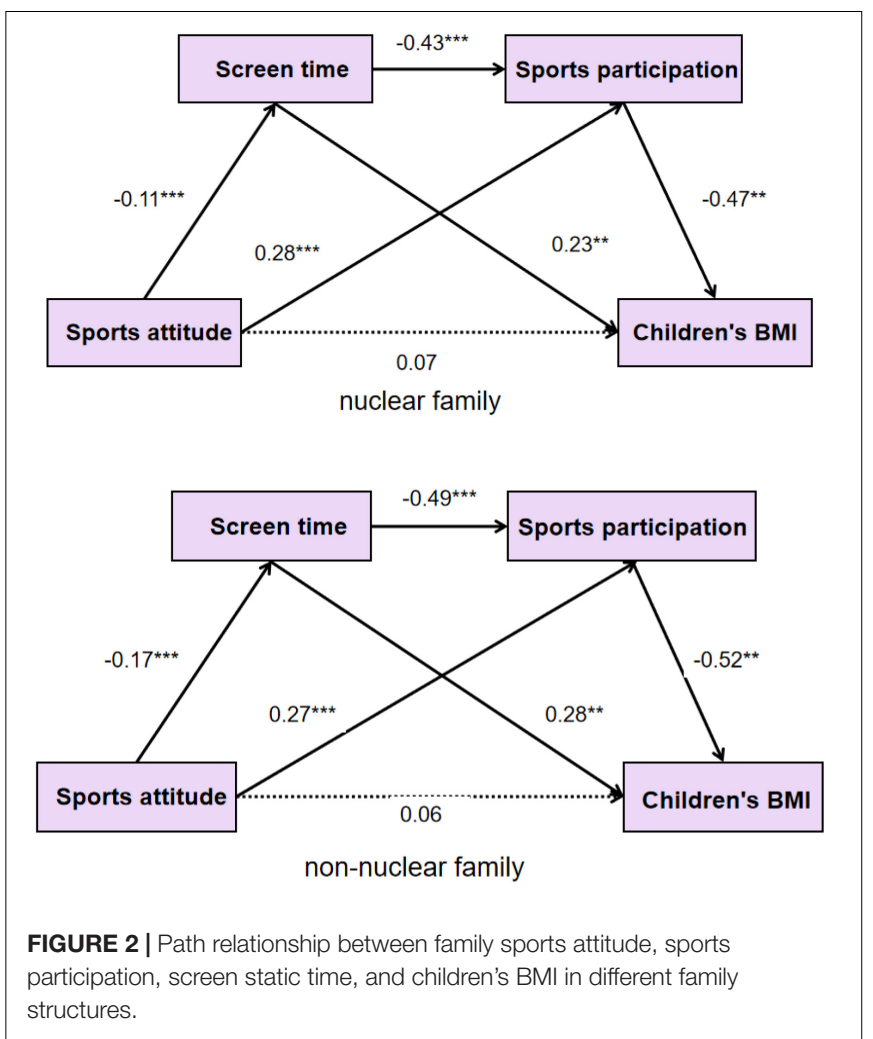

(Duch et al., 2013; Carson et al., 2017; Monserrat et al., 2020; Yañez et al., 2020). Wang et al. (2015) found in their research that the concept of exercise will gradually internalize into selfidentity with the improvement of the education level, and the influence of the education level on physical exercise behavior will be increasingly enhanced. Therefore, parents' education levels have a profound influence on family physical exercise.

\section{Family Sports Attitude and Children's BMI}

There is a significant negative correlation between family sports attitude and children's BMI, which is consistent with the previous research results of Gao Yan et al. A large number of studies have shown that the decisions of children's sports participation at the beginning, middle, and end are related to the environment. Human behavior is formed by the interaction between individuals and the environment. The environmental models that affect human development include micro, medium, and macro-environmental models. Family is an important part of the microenvironment, which plays a key role in the process of children's growth (Sun et al., 
2006; Jian et al., 2014; Yang et al., 2014). Family is not only the "gatekeeper" of children's sports activities but also the key factor of children's screen time duration (Strasburgerand Council on Communications and Media American Academy of Pediatrics, 2010). Effective intervention measures aimed at family factors can affect children's physical condition. Therefore, a better understanding of the influence of family sports attitude on children's physical health is helpful to reduce the incidence of childhood obesity and malnutrition caused by family factors. Previous studies have shown that the influence of family, parents, and elders on children's sports behavior can be divided into two aspects: the support of elders for children's sports and the shaping of the role model of elders (Clark et al., 2011; Morgan et al., 2012; Rhodes and Quinlan, 2014). All the above results indicate the importance of family sports attitude in children's physical health among the influencing factors of the family on children's physical health, and family should be regarded as the implementation focus of children's physical health intervention.

\section{Chain-Mediated Effects of Children's Screen Time and Exercise Participation}

In this study, screen time and sports participation were used as mediating variables to construct a mediating model of family sports attitudes affecting children's BMI. The mediating effect of sports participation and screen time is significant, which indicates that they played an important role in family sports attitudes in interpreting children's BMI. Fan Huiying et al. found that family support has a significant impact on children's physical activities, and family as the starting point of children's sports participation there was the strongest correlation between their support for children's physical activity attitude and children's sports (Craggs et al., 2011; Yao and Rhodes, 2015; Pyper et al., 2017; Hutchens and Lee, 2018). So, family sports attitudes play an important role in young children's sports participation and static screen time limitation. Parents, as the first teachers of children's physical education class, will have a positive impact on children's sports by setting an example in sports participation and supporting the concept of physical education, whereas the negative performance of family physical education attitude and behavior will have a negative impact on children. Reilly et al. (2014) found that Scottish children's physical fitness declined due to insufficient sports participation in recent years. One important and direct reason is that parents have a negative attitude toward sports participation (Reilly et al., 2014). Researchers found that the longer children's moderateintensity activity time was, the shorter their screen time was, which was related to children's family sports cognition (Wärnberg et al., 2021). This view was consistent with the results of this study. Parents' support for children's sports can improve their children's sports participation, while children's sports exercise is negatively correlated with children's BMI (Brown et al., 2016). Sports attitude can influence children's BMI through sports participation. Another important factor affecting BMI is sedentary behavior, which includes screen time, homework time, and so on. Related studies have found that sedentary behavior mainly based on screen time has a negative impact on health problems such as overweight and myopia in adolescents and children. Moreover, the study found that family and peer support had a significant impact on sedentary screen time, and parents' support for children's physical activity was negatively correlated with screen time (Biddle, 2007; Vander Ploeg and Hillsdon, 2017). It can be seen that the family environment constitutes an external driving force for children's screen time, which is mainly manifested in exercise support and participation. When family members form a state of "high screen time-low exercise time," children's screen time can be invisibly increased, thus leading to the increase of their BMI. This indicates that the mediating effect of screen time and exercise participation in this research model is feasible, and it can be seen from Figure 1 that the mediating effect is completely mediating. To some extent, this result explained the influence mechanism of family sports attitude on children's BMI and provided evidence for the intervention of family factors in children's physical health development.

\section{Differences in Mediating Effects of Screen Time and Exercise Participation Among Different Family Structures}

Screen time and exercise participation were fully mediating effects in different family structures, and the chain-mediated effects held in both nuclear and non-nuclear families. In the family structure, the nuclear family is the family composed of husband and wife and unmarried children, while the nonnuclear family includes three generations living under the same family, single parent, and grandparenting families. This study found that the total mediating effect of screen time and exercise participation in non-nuclear families was higher than those in nuclear families, which may be related to the higher proportion of three generations living in the same family in non-nuclear families. The family structure of three generations under one roof is the most abundant and complete. Children grow up in this environment with both parents and grandparents. The study found that grandparents had more time and energy to spend with and participate in children's activities than busy parents. However, the lack of parents' company and upbringing may result in children's bad health behavior habits due to the lack of scientific sports knowledge, nutrition knowledge, and poor health concept of their grandparents (Huang and Chen, 2007). Therefore, both parents and grandparents play important roles in the development of healthy behaviors in young children. In this study, there were significant differences in children's family sports attitude, sports participation, and screen time among different family structures, but there was no significant difference in the mediating role model of sports participation and screen time. The results indicated that the three factors of family sports attitude, sports participation, and screen time were different due to the influence of family structure variables, but the chain-mediating effect of sports participation and screen time in the influence mechanism of family sports attitude on children's BMI had internal similarities among different children's family structures. 


\section{CONCLUSION AND PROSPECT}

\section{Conclusion}

There are significant differences in children's family sports attitude, sports participation, screen time, and BMI with different parents' education levels. Specifically, the higher the parents' education levels, the higher the family sports attitude score, the better the sports participation, and the lower the screen time. Family sports attitude is positively correlated with sports participation and a mother's education level and negatively correlated with children's screen static time and BMI. Sports participation and screen time play a completely mediating role in the influence path of family sports attitude on children's BMI. The mediating mechanisms of sports participation and screen time were not affected by family structure (nuclear and non-nuclear families), but the total mediating effect of sports participation and screen time was higher in non-nuclear families than in nuclear families. The results of this study will provide a useful reference for teachers and parents to control children's physical health and the influencing factors of children's physical health research in the future.

\section{Limits and Prospects}

This study identified the mediating role of sports participation and screen time. The structural equation model of the relationship between the attitude of plus family and children's BMI was constructed and verified. And the study still has the following limitations and suggestions for future research:

(1) Among the family influencing factors of children's BMI, this study focused on examining the mediating effects of children's sports participation and static screen time.

(2) This study was a cross-sectional study. Future research can further support the conclusion of this study by using the

\section{REFERENCES}

Basterfield, L., Adamson, A. J., Frary, J. K., Parkinson, K. N., Pearce, M. S., Reilly, J. J., et al. (2011). Longitudinal study of physical activity and sedentary behavior in children. Pediatrics 127, e24-e30. doi: 10.1542/peds.20101935

Beaulieu, K., Hopkins, M., Blundell, J., and Finlayson, G. (2016). Does habitual physical activity increase the sensitivity of the appetite control system? A systematic review. Sports Med. 46, 1897-1919. doi: 10.1007/s40279-0160518-9

Best, J. R. (2012). Exergaming immediately enhances children's executive function. Dev. Psycho1. 48, 1501-1510. change doi: 10.1037/a0026648

Biddle, S. J. H. (2007). Sedentary behavior. Am. J. Prev. Med. 33, 502-504. doi: 10.1016/j.amepre.2007.08.002

Bradley, R. H., and Corwyn, R. F. (2002). Socioeconomic status and child development. Annu. Rev. Psychol. 53, 371-399. change doi: 10.1146/annurev. psych.53.100901.135233

Brown, B. B., and Larson, J. (2009). "Peer relationships in adolescence," in Handbook of Adolescent Psychology[M]. eds R. M. Lerner and L. D. Steinberg (Hoboken, NJ: John Wiley \& Sons Inc.) doi: 10.1002/9780470479193. adlpsy002004

Brown, H. E., Atkin, A. J., Panter, J., Wong, G., Chinapaw, M., and Van Sluijs, E. M. (2016). Family-based interventions to increase physical activity in children: a systematic review, meta-analysis and realist synthesis. Obes. Rev. 17, 345-360. doi: 10.1111/obr.12362 exercise tracking method and providing direct evidence for variable causality.

\section{DATA AVAILABILITY STATEMENT}

The original contributions presented in the study are included in the article/supplementary material, further inquiries can be directed to the corresponding author/s.

\section{ETHICS STATEMENT}

The studies involving human participants were reviewed and approved by the Ethics Committee of Sports School of Southwest University in China. Written informed consent to participate in this study was provided by the participants' legal guardian/next of kin.

\section{AUTHOR CONTRIBUTIONS}

$\mathrm{CP}$ and LJ carried out the protocol and the questionnaire survey. YL recruited the survey respondents. $\mathrm{ZT}, \mathrm{LH}$, and YJ undertook the statistical analysis and graphical representation of the data. LW revised the draft. All authors participate in the completion of the study and contributed to and approved the final manuscript.

\section{FUNDING}

This work was supported by the National Social Science Foundation of China (Grant No: 19ZDA352).

Budde, H., Voelcker-Rehage, C., Pietrabyk-Kendziorra, S., Ribeiro, P., and Tidow, G. (2008). Acute coordinative exercise improves intentional performance in adolescents. Neurosci. Lett. 441, 219-223. doi: 10.1016/j.neulet.2008.06.024

Carson, V., Chaput, J. P., Janssen, I., and Tremblay, M. S. (2017). Health associations with meeting new 24-hour movement guidelines for Canadian children and youth. Prev. Med. 95, 7-13. doi: 10.1016/j.ypmed.2016.12.005

Carson, V., Hunter, S., Kuzik, N., Gray, C. E., Poitras, V. J., Chaput, J. P., et al. (2016). Systematic review of sedentary behavior and health indicators in schoolaged children and youth: an update. Appl. Physiol. Nutr. Metab. 41(6 Suppl 3), S240-S265. doi: 10.1139/apnm-2015-0630

Chen, S. B., and Yu, B. (2020). The influence of the characteristics of information providers on children's selective trust. J. Educ. Academic Monthly 58-64.

Cheng, G., Lu, J., and Chen, Z. (2020). The influence of family capital on the physical health of middle school students. Res. Educ. Sci. 1009-817X (2020) 11-0044-07,

Clark, M. I., Spence, J. C., and Holt, N. (2011). In the shoes of young adolescent girls: understanding physical activity experiences through the interpretive description. Qual. Res. Sport Exerc. Health 3, 193-210. doi: 10.1080/2159676X. 2011.572180

Cole, T. J., and Lobstein, T. (2012). Extended international (IOTF) body mass index cut-offs for thinness, overweight and obesity. Pediatr. Obes. 7, 284-294. change doi: 10.1111/j.2047-6310.2012.00064.x

Craggs, C., Corder, K., van Sluijs, E. M. F., and Griffin, S. J. (2011). Determinants of change in physical activity in children and adolescents a systematic review. Am. J. Prev. Med. 40, 645-658. doi: 10.1016/j.amepre.2011.02.025 
de Onis, M., Onyango, A. W., Borghi, E., Siyam, A., Nishida, C., Siekmann, J. (2007). Development of a WHO growth reference for school-aged children and adolescents. Bull. World Health Organ. 85, 660-667. doi: 10.2471/BLT.07. 043497

Dietz, W. H., and Robinson, T. N. (1998). Use of the body mass index (BMI) as a measure of overweight in children and adolescents. J. Pediatr. 132, 191-193. change doi: 10.1016/S0022-3476(98)70426-3

Dong, Y.-H., Yang, Z.-G., et al. (2018). The influence of family supportive environment for physical exercise on the physical quality of primary and middle school students. Chinese school health 39, 1297-1300.

Duch, H., Fisher, E. M., Ensari, I., and Harrington, A. (2013). Screen time use in children under 3 years old: a systematic view of correlates. Int. J. Behav. Nutr. Phys. Act. 10:102. doi: 10.1186/1479-5868-10-102

Fitzgibbon, M. L., Stolley, M., Schiffer, L., Van Horn, L., KauferChristoffel, K., and Dyer, A. (2004). Two-year follow-up results for hip-hop to health jr.: a randomized controlled trial for overweight prevention in preschool minority children. J. Pediatr. 146, 618-625. 10.1016/j.jpeds.2004.12.019, doi: 10.1016/j. jpeds.2004.12.019

Foster, C., Moore, J. B., Singletary, C. R., and Skelton, J. A. (2018). Physical activity and family-based obesity treatment: a review of expert recommendations on physical activity in youth. Clin. Obes. 8, 68-79. doi: 10.1111/cob. 12230

Fox, K. R. (1999). The influence of physical activity on mental well-being. Public Health Nutr. 2, 411-418. doi: 10.1017/S1368980099000567

Freedman, D. S., Khan, L. K., Serdula, M. K., Dietz, W. H., Srinivasan, S. R., and Berenson, G. S. (2005). The relation of childhood BMI to adult adiposity: the Bogalusa heart study. Pediatrics 115, 22-27. doi: 10.1542/peds.20040220

$\mathrm{Fu}, \mathrm{M}$., and $\mathrm{Li}, \mathrm{B}$. (2004). The effects of parental support and peer friendship quality on adolescent sports motivation and engagement. J. Beijing Sport Univ. 1007-3612(2004) 10-1340-03,

Gerbing, D. W., and Anderson, J. C. (1988). An updated paradigm for scale development incorporating unidimensionality and its assessment. J. Mark. Res. 25, 186-192. doi: $10.2307 / 3172650$

Han, H., Tang, J., and Zhang, Q. (2016). Prevention, 20. 1008Ü-1010. Analysis on the status and family Influencing Factors of eating Behavior of 4-6 years old children in Bengbu City [J]. Chinese Journal of Disease Control and Prevention, 20. 1008-1010.

Hoare, E., Crooks, N., and Hayward, J. (2019). Associations between combined overweight and obesity, lifestyle behavioral risk and quality of life among Australian regional school children: baseline findings of the Goulburn Valley health behaviors monitoring study. Health Qual. Life Outcomes 17:16. doi: 10.1186/s12955-019-1086-0

Hu, F. B., Willett, W. C., Li, T., Stampfer, M. J., Colditz, G. A., and Manson, J. E. (2004). Adiposity as compared with physical activity in predicting mortality among women. N. Engl. J. Med. 351, 2694-2703. doi: 10.1056/NEJMoa042135

Huang, S., and Chen, X. (2007). A review of the research on intergenerational education. Science of Modern Education 16, 63-65.

Hutchens, A., and Lee, R. E. (2018). Parenting practices and children's physical activity: an integrative review. J. Sch. Nurs. 34, 68-85. change doi: 10.1177/ 1059840517714852

Jian, Y., Kaimei, C., and Liu, J. (2014). The influence of exercise time on adolescent sports commitment: the mediating role of exercise satisfaction and social support. Journal of Shanghai Institute of Physical Education 69-73.

Ledoux, S., Miller, P., Choquet, M., and Plant, M. (2002). Family structure, parentchild relationships and alcohol, and other drug use among teenagers in France and the United Kingdom. Alcohol Alcohol. 37, 52-60. doi: 10.1093/alcalc/ 37.1 .52

Liu, Y., Chen, S., et al. (2021). The background, construction, application and future development of the Chinese children and adolescents' sports literacy evaluation system. J. Shanghai Institute Phys. Educ. 45, 19-26.

Lu, F., Song, Y., Liu, L., Fang, X., and Zhang, C. (2020). The effects of intergenerational education on grandchildren and grandparents: a two-edge swords effect. Adv. Psychol. Sci. 28, 1733-1741. doi: 10.3724/SP.J.1042.2020. 01733

Lu, F. R., Wang, X., Li, D. F., and Wang, Y. (2015). Research on the characteristics of primary school adjustment and its relationship with parenting style. Psychol. Dev. Educ. 31, 555-562.
Matthews, K. A., and Gallo, L. C. (2011). Psychological perspectives on pathways linking socioeconomic status and physical health. Annu. Rev. Psychol. 62, 501-530. doi: 10.1146/annurev.psych.031809.130711

Monserrat, P., Miquel, B. V., and Aina, M. Y. (2020). Maternal education level and excessive recreational screen time in children: a mediation analysis. Int. J. Environ. Res. Public Health 17:8930. doi: 10.3390/ijerph17238930

Morgan, I. G., Ohno, M., and Saw, S. M. (2012). Myopia. Lancet 379, 1739-1748. doi: 10.1016/S0140-6736(12)60272-4

Ng, M., Fleming, T., Robinson, M., Thomson, B., Graetz, N., Margono, C., et al. (2014). Global, regional, and national prevalence of overweight and obesity in children and adults during 1980-2013: a systematic analysis for the global burden of disease study 2013. Lancet 384, 766-781. doi: 10.1016/S01406736(14)60460-8

Pons, M., Bennasar-Veny, M., Yañez, A. M. (2020). Maternal education level and excessive recreational screen time in children: a mediation analysis. Int. J. Environ. Res. Public Health 17:8930. doi: 10.3390/ijerph17238930

Pooja, S. T., Chuan, Z., James, F. S., Kelli, L. C., Lawrence, D. F., and Brian, E. S. (2016). Home environment relationships with children's physical activity, sedentary time, and screen time by socioeconomic status. Int. J. Behav. Nutr. Phys. Act. 9:88. doi: 10.1186/1479-5868-9-88

Pyper, E., Harrington, D., and Manson, H. (2017). Do parents' support behaviors predict whether or not their children get sufficient sleep? A cross-sectional study. BMC Public Health 17:432. doi: 10.1186/s12889-017-4334-4

Qian, L., Zhang, F., Newman, I. M., Shell, D. F., and Du, W. (2018). Effects of selected socio-demographic characteristics on nutrition knowledge and eating behavior of elementary students in two provinces in China. BMC Public Health 18:21. doi: 10.1186/s12889-017-4580-5

Quarmby, T., Dagkas, S., and Bridge, M. (2011). Association between children's physical activities, sedentary behaviors and family structure: a sequential mixed methods approach. Health Edu. Res. 26, 63-76. doi: 10.1093/her/cyq071

Reaven, G. M. (2011). Insulin resistance: the link between obesity and cardiovascular disease. Med. Clin. North Am. 95, 875-892. change doi: 10.1016/ j.mcna.2011.06.002

Reilly, J. J., Dick, S., McNeill, G., and Tremblay, M. S. (2014). Results from Scotland's 2013 report card on physical activity for children and youth. J. Phys. Act. Health. 11, S93-S97. doi: 10.1123/ipah.2014-0183

Reilly, J. J., Kelly, L., Montgomery, C., Williamson, A., Fisher, A., McColl, J. H., et al. (2006). Physical activity to prevent obesity in young children: cluster randomized controlled trial. BMJ 333:1041. doi: 10.1136/bmj.38979.623773.55 Rhodes, R. E., and Quinlan, A. (2014). "The family as a context for physical activity promotion," in Group Dynamics in Exercise and Sports Psychology, 2nd Edn. eds M. R. Beauchamp and M. A. Eys (New York, NY: Routledge), 203-221. doi: 10.4324/9780203794937-12

Shi, X. R., An, M. J., Chen, T. J., and Ma, J. (2021). The role of milk-drinking behavior in the relationship between family socioeconomic status and body mass index of children and adolescents. Beijing Da Xue Xue Bao Yi Xue Ban $53,308-313$.

Shi, Y., Huang, W. Y., Sit, C. H. P., and Wong, S. H. S. (2020). Compliance with 24hour movement guidelines in Hong Kong adolescents: associations with weight status. J. Phys. Act. Health 17, 287-292. doi: 10.1123/jpah.2019-0230

Singh, A. S., Mulder, C., Twisk, J. W., van Mechelen, W., and Chinapaw, M. J. (2008). Tracking of childhood overweight into adulthood: a systematic review of the literature. Obes. Rev. 9, 474-488. doi: 10.1111/j.1467-789X.2008.00 475. $x$

Strasburger, V. C. and Council on Communications and Media American Academy of Pediatrics (2010). Media education. Pediatrics. 126, 1012-1017. doi: 10.1542/peds.2010-1636

Sun, Y., Liu, L., Ye, J., et al. (2006). A study on internal motivation and goal orientation in youth sports activities. J. Tianjin Inst. Phys. Educ. 108-110.

Thivel, D., Tremblay, M. S., and Chaput, J. P. (2013). Modern sedentary behaviors favor energy consumption in children and adolescents. Curr. Obes. Rep. 2, 50-57. doi: 10.1007/s13679-012-0032-9

Timperio, A. F., van Stralen, M. M., Brug, J., Bere, E., Chinapaw, M. J., De Bourdeaudhuij, I., et al. (2013). Direct and indirect associations between the family physical activity environment and sports participation among 10-12-year-old European children: testing the EnRG framework in the ENERGY project. Int. J. Behav. Nutr. Phys. Act. 10:15. doi: 10.1186/1479-58 68-10-15 
Van Ekris, E., Altenburg, T. M., Singh, A. S., Proper, K. I., Heymans, M. W., and Chinapaw, M. J. M. (2016). An evidence-update on the prospective relationship between childhood sedentary behavior and biomedical health indicators: a systematic review and meta-analysis. Obes. Rev. 17, 833-849. doi: 10.1111/obr. 12426

Vander Ploeg, H. P., and Hillsdon, M. (2017). Is sedentary behavior just physical inactivity by another name? Int. J. Behav. Nutr. Phy. 14:142. change doi: 10 . 1186/s12966-017-0601-0

Wang, F., Jiang, C., Wang, M., et al. (2015). Research on the intergenerational variation of adult female physical exercise behavior and its influencing factors. Sports Sci. 35, 24-34.

Wang, M., Wen, X., Lu, Y., and Liu, Y. (2012). The influence of family structure on adolescent health behavior. Sports Sci. 32, 34-41.

Wärnberg, J., Pérez-Farinós, N., Benavente-Marín, J. C., Gómez, S. F., Labayen, I., Zapico, A. G., et al. (2021). Screen time and parents' education level are associated with poor adherence to the Mediterranean diet in Spanish children and adolescents: the PASOS study. J. Clin. Med. 10:795 doi: 10.3390/ jcm10040795

Yañez, A. M., Bennasar-Veny, M., Leiva, A., and García-Toro, M. (2020). Implications of personality and parental education on healthy lifestyles among adolescents. Sci. Rep. 10:7911. doi: 10.1038/s41598-020-64850-3

Yang, C., Tang, Y., Zhang, H., et al. (2014). Research on the effective implementation path of adolescent physical health policy. Sports Sci. 34, 56-64.

Yao, C. A., and Rhodes, R. E. (2015). Parental correlates in child and adolescent physical activity: a meta-analysis. Int. J. Behav. Nutr. Phys. Act. 12:10. change doi: 10.1186/s12966-015-0163-y

Zhang, Y., Huang, J., and Jiang, C. (2019). Analysis on the changing trend and influencing factors of physical quality of children in Macao. China Sports Sci. Technol. 55, 49-58.
Zhang, Y., Quan, H., Zhang, Q., Jia, Y., and Sun, B. (2017). The degree of sports participation and its intervention in the intergenerational rearing of children Preschool Education Research. 28-37.

Zhao, B. H. (2007). Measurement equivalence test and implementation of AMOS. China Health Stat. 24,

Zhonglin, W., and Baojuan, Y. (2014). Analyses of mediating effects: the development of methods and models. Adv. Psychol. Sci. 22, 731-745. doi: 10. 3724/SP.J.1042.2014.00731

Zhou, Z., Ren, H., and Yin, Z. (2014). A policy-driven multifaceted approach for early childhood physical fitness promotion: impactson body composition and physical fitness in young Chinese children. BMC Pediatr. 14:118. doi: 10.1186/1471-2431-14-118

Conflict of Interest: The authors declare that the research was conducted in the absence of any commercial or financial relationships that could be construed as a potential conflict of interest.

Publisher's Note: All claims expressed in this article are solely those of the authors and do not necessarily represent those of their affiliated organizations, or those of the publisher, the editors and the reviewers. Any product that may be evaluated in this article, or claim that may be made by its manufacturer, is not guaranteed or endorsed by the publisher.

Copyright (0) 2021 Lian, Peijie, Kun, Tingran, Hengxu, Jinxin, Wenyun and Jiong. This is an open-access article distributed under the terms of the Creative Commons Attribution License (CC BY). The use, distribution or reproduction in other forums is permitted, provided the original author $(s)$ and the copyright owner(s) are credited and that the original publication in this journal is cited, in accordance with accepted academic practice. No use, distribution or reproduction is permitted which does not comply with these terms. 